\title{
The research of the properties of thin films of molybdenum to form the contact masks for diffractive optics elements
}

\author{
Poletaev S.D. \\ Image Processing Systems Institute, Russian Academy of Sciences, \\ Samara State Aerospace University
}

\begin{abstract}
Researched the parameters of the microstructures, obtained by laser termochemical space recording in films of molybdenum with a thickness of 17, 35 and $70 \mathrm{~nm}$, deposited on a glass and quartz substrates. Graphs of the spatial resolution of the microstructures as a function of the laser power are plotted for different substrate materials. It is shown that a higher spatial resolution of the microstructures can be achieved in the molybdenum films with a $17 \mathrm{~nm}$ thickness.
\end{abstract}

Keywords: microstructure, laser ablation, thermal recording of a molybdenum film, glass and quartz substrates

Citation: Poletaev S.D. The research of the properties of thin films of molybdenum to form the contact masks for diffractive optics elements. Proceedings of Information Technology and Nanotechnology (ITNT-2015), CEUR Workshop Proceedings, 2015; 1490: 90-96. DOI: 10.18287/1613-00732015-1490-90-96

\section{Introduction}

It seems promising to use in various fields of science and technology of diffractive optical elements (DOE), which are plates formed on their surface microstructure [1, 2]. The most important stage of manufacture of the microreliefs is get contact mask resistant to plasma-chemical processes necessary to transmit the calculated microstructure of the DOE in the substrate. Previously this had been circulated lithographic (wet) technology [3-8].

At the present time to reduce the dimensions of the microstructures, the widely used method of formation of topological drawing directly in the source layer of the material of the contact mask without the use of photoresists. It is based on local processing of thin films of chromium focused laser radiation [9, 10], under the influence of which is thermochemical conversion of the surface layer of the work material.

The disadvantage of this technology is the low resolution of about $0.8 \mu \mathrm{m}$. Therefore urgency to the task of developing techniques that allow to overcome this barrier. This result is possible through search and application of materials with 
contrasting characteristics to selectively use a maximum of activating radiation. In this respect, a well-known series of works, where instead of chrome offers a variety of alternative materials, such as silicon, indium phosphide and the oxides of various metals [11-13]. Unlike standard technologies they propose to form a microstructure by evaporation (ablation) of material.

In [14] have demonstrated the possibility of ablation of molybdenum films with a thickness of about $0.5 \mu \mathrm{m}$ picosecond laser beam with a wavelength of $1064 \mathrm{~nm}$, deposited on a sublayer of silicon nitride thickness of about $140 \mathrm{~nm}$. The grounds were glass substrate of a thickness of $3 \mathrm{~mm}$.

Based on [14], we proposed an approach based on the ablation areas of the film of molybdenum exposed to laser radiation [15].

The purpose of this work is to study the feature of the contact mask, obtained by laser ablation of films of molybdenum, depending on the thickness of the films, which will produce the optimum conditions of carrying out the process.

\section{Methods and materials}

The base served as an optically smooth substrate made of glass and fused quartz brand KV of size $50 \times 50 \mathrm{~mm}$, thickness $3 \mathrm{~mm}$. Film of molybdenum with a thickness of 17,35 and $70 \mathrm{~nm}$ were deposited by magnetron sputtering method on the "Caroline $\mathrm{D}-12 \mathrm{~A}$ " under the following conditions: the power of the magnetron is $700 \mathrm{~W}$, the temperature of the substrate is $200^{\circ} \mathrm{C}$, a pressure of argon to $2.0 \cdot 10-1 \mathrm{~Pa}$. The time of deposition was determined by the finite thickness of the films and ranged from 2 to 8 $\min$.

Patterns in the films formed on the laser writing station CLWS-200 [16-18].

Recording was conducted under the following conditions: operating wavelength of the laser radiation is $488 \mathrm{~nm}$; maximum power supplied to the recording head $100 \mathrm{~mW}$; record structure - concentric rings with a pitch of $3 \mu \mathrm{m}$ and an outer radius of $3 \mathrm{~mm}$; the magnitude of the power for each ring decreased from $100 \%$ at the point of greatest radius to 0 in the centre with a step of $0.5 \%$. The speed of rotation of the sample - about $10 \mathrm{~s}^{-1}$. the Specified parameters of the process corresponded to the maximum power density of laser radiation $\mathrm{E}_{\max }=2 \cdot 10^{7} \mathrm{~W} / \mathrm{cm}^{2}$. The effect of laser radiation led to local evaporation thin film of molybdenum over the entire thickness.

The morphology and elemental composition of the surface of the nanostructures were studied using scanning electron microscope (SEM) Hitachi TM3030 with integrated EDS spectrometer.

\section{Analysis of the results}

In Fig. 1 shows the dependence of the width of the lanes from the laser output power for a radius record of $3 \mathrm{~mm}$. Dependence obtained for quartz and glass substrates. The width of the recorded tracks in the first place, depends linearly on the laser power. When they are the same width for quartz substrates requires approximately $20 \%$ more power, due to the difference in the thermophysical properties of quartz and glass. Quartz, having a larger thermal conductivity, assigns laser energy from the field of film. Film thickness of $17 \mathrm{~nm}$ show higher spatial resolution, $2500 \mathrm{~mm}^{-1}$, against $1500 \mathrm{~mm}^{-1}$ for films with a thickness of $35 \mathrm{~nm}$. The permissions that are close to the maximum was reached in the power density in the 
range $(0,7 \ldots 1,2) \cdot 10^{7} \mathrm{~W} / \mathrm{cm}^{2}$. Note that this is significantly less than the theorical values obtained, for instance, in [11].

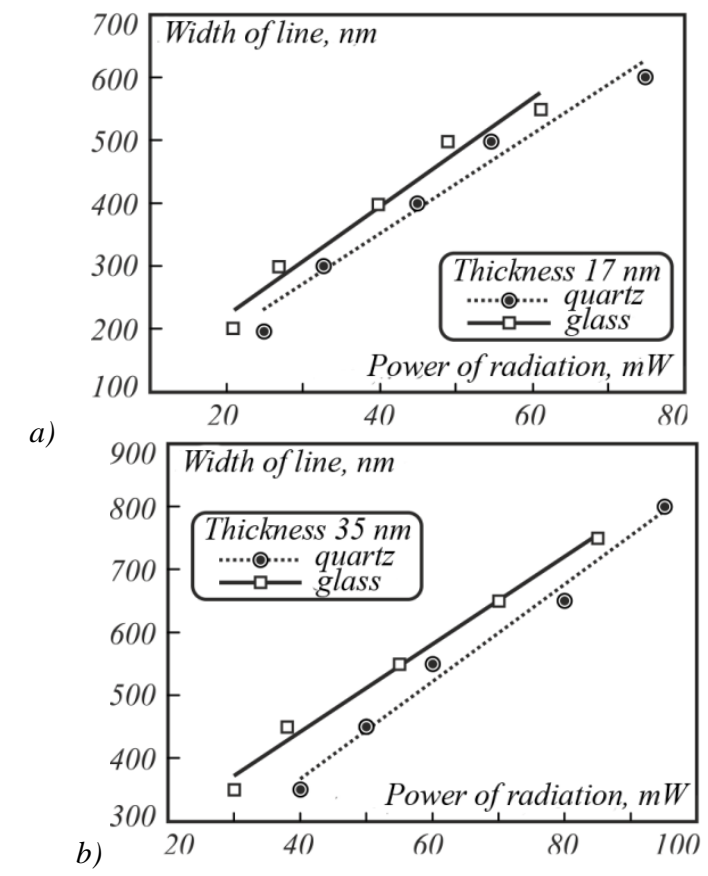

Fig. 1. - The dependence of the line width of the nanostructure on the power of laser radiation for films with a thickness of $17 \mathrm{~nm}$ (a) and for films with a thickness of $35 \mathrm{~nm}$ (b)

Presented on Fig. 2 pictures of SAM films with a thickness of $35 \mathrm{~nm}$, exposed to the laser beam, allow the edges of the tracks to watch the products of destruction as representing a zone of thermal influence. Most likely, their emergence with the removal of a significant portion of the substance from the area of reactive ablation recoil pressure PA-world jet [19]. As shown earlier, their height does not exceed the thickness of the film [15].

For films with a thickness of $17 \mathrm{~nm}$, the formation of degradation products is not typical (Fig. 3). This can be explained by the fact that the energy of laser radiation is enough for a quick and complete evaporation of the material at the point of impact. For these two cases are well for-markedly boundary of the critical power at which the evaporation of the metal stops. Also around tracks observed subtle trace of a width equal to the diameter of the laser spot. Probably, this area needs to impose restrictions on the minimum recording period. For films with a thickness of $70 \mathrm{~nm}$ of the radiation energy is insufficient for the formation of tracks even in areas with a minimum radius of recording (Fig. 4). It is important to note the following. For systems with circular scanning absorbed by the material energy (dose) of laser radiation at a constant power density varies with the radius record, since the radius of the record specifies an effective time of exposure. The decrease of power density from the edge to the center with simultaneous increase of exposure time to have an opposite effect on the magnitude of the radiation energy. However, in our case a 
decrease in the size of the track as you approach the center, that allows claim about the decrease of the absorbed energy.

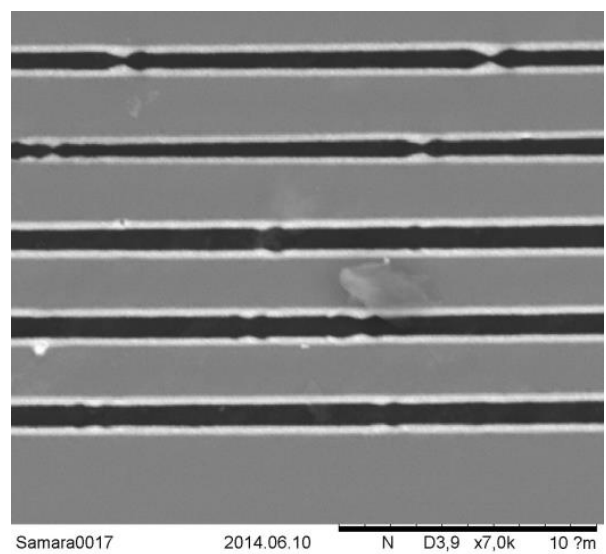

Fig. 2. - The SEM picture of the surface nanostructures on film of molybdenum with a thickness of $35 \mathrm{~nm}$
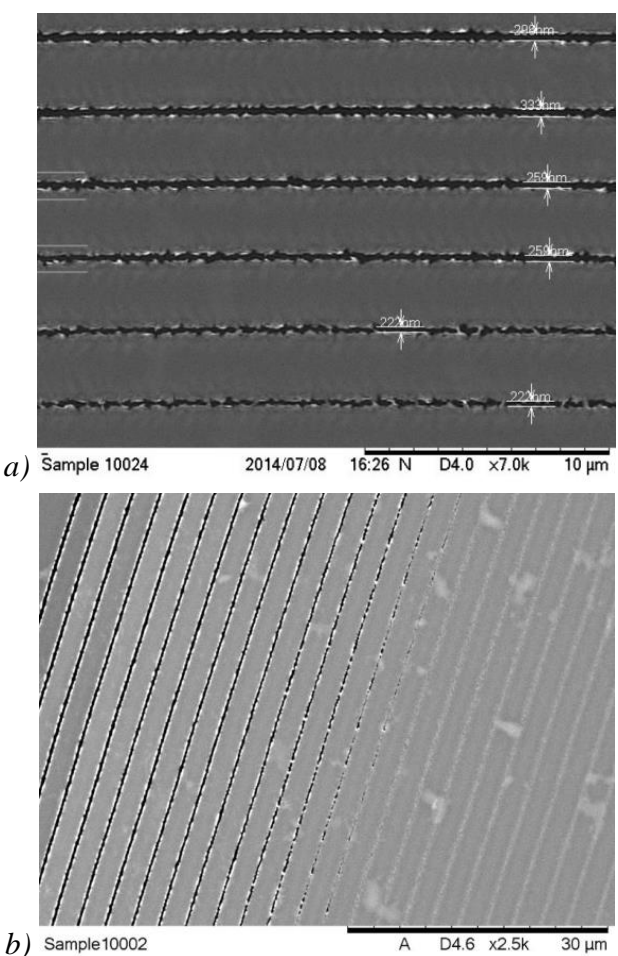

Fig. 3. - The SEM picture of the surface nanostructures on film of molybdenum with a thickness of $17 \mathrm{~nm}$ : the shape and the characteristic sizes of tracks (a) General view (b) 


\section{Conclusion}

The study of microstructures of metallic patterns of the DOE showed that the best spatial resolution and minimum defects in the figure of the mask is achieved at a film thickness of molybdenum $17 \mathrm{~nm}$.

Minimum attainable period of record limit width trace of the laser spot and is in our case $0.8 \mu \mathrm{m}$. Spatial resolution will be limited to this value and can be increased by reducing the wavelength and, correspondingly, the diameter of the laser spot.

Given the fact that the selectivity of the plasma etching films of molybdenum relative to quartz can reach several hundred, the result opens the way for the creation of structures with submicron resolution, in particular, short-focus of the DOE, and also allows you to create patterns with a minimum number of manufacturing operations. In addition, as described in the article, the research is also relevant for the development of certain laser technology [20 - 22].

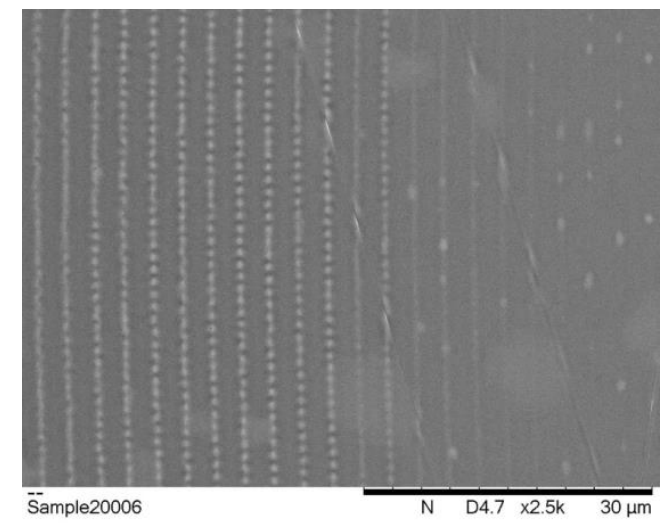

Fig. 4. - The SEM picture of the surface nanostructures on film of molybdenum with a thickness of $70 \mathrm{~nm}$

\section{Acknowledgements}

The work was supported by RFBR (grant No. 14-07-00177a). The authors Express gratitude to the company "INTERLAB" (Russia, Moscow) for their help in the study of samples on the microscope Hitachi TM.

\section{References}

1. Soifer VA, Kotlyar VV, Kazanskiy NL, Doskolovich LL, Kharitonov SI, Khonina SN, Pavelyev VS, Skidanov RV, Volkov AV, Golovashkin DL, Solovyev VS, Usplenyev GV. Methods for Computer Design of Diffractive Optical Elements. Edited by V.A. Soifer. New York: John Wiley \& Sons. Inc., 2002. 765 p.

2. Golovashkin DL, Doskolovich LL, Kazanskiy NL, Kotlyar VV, Pavelyev VS, Skidanov RV, Soifer VA, Khonina SN. Diffractive computers optics. Edited by V.A. Soifer. Moscow: FIZMATLIT Publisher, 2007. 736 p. [in Russian]

3. Volkov AV, Kazanskiy NL, Rybakov OYe. The study of plasma etching technology for creation of multi-level diffractive optical elements. Computer Optics, 1998; 18: 127-130. [in Russian] 
4. Volkov AV, Kazanskiy NL, Rybakov OYe. Development of technology for creation of diffractive optical elements with submicron dimensions of the relief in the silicon wafer. Computer Optics, 1998; 18: 130-133. [in Russian]

5. Kazanskii NL, Kolpakov VA, Kolpakov AI. Anisotropic etching of $\mathrm{SiO}_{2}$ in high-voltage gas-discharge plasmas. Russian Microelectronics, 2004; 33(3): 169-182.

6. Pavelyev VS, Borodin SA, Kazanskiy NL, Kostyuk GF, Volkov AV. Formation of diffractive microrelief on diamond film. Optics \& Laser Technology, 2007; 39(6): 12341238.

7. Bezus EA, Doskolovich LL, Kazanskiy NL. Evanescent-wave interferometric nanoscale photolithography using guided-mode resonant gratings. Microelectronic Engineering, 2011; 88(2): 170-174.

8. Bezus EA, Doskolovich LL, Kazanskiy NL. Interference pattern formation in evanescent electromagnetic waves using waveguide diffraction gratings. Quantum Electronics, 2011; 41(8): 759-764. doi: 10.1070/QE2011v041n08ABEH014500.

9. Veiko VP, Korol'kov VI, Poleshchuk AG, Sametov AR, Shakhno EA, Yarchuk MV. Study of the spatial resolution of laser thermochemical technology for recording diffraction microstructures. Quantum Electronics, 2011; 41(7): 631-636. [in Russian]

10. Veiko VP, Sinev DA, Shakhno EA, Poleshchuk AG, Sametov AR, Sedukhin AG. Researching the features of multibeam laser thermochemical recording of diffractive microstructures. Computer Optics, 2012; 36(4): 562-571.

11. Krause S, Miclea T, Steudel F, Schweizer S, Seifert G. Precise microstructuring of indium-tin oxide thin films on glass by selective femtosecond laser ablation. EPJ Photovoltaics, 2013; 4(40601): p1-p5.

12. Zoppel S, Huber H, Reider GA. Selective ablation of thin Mo and TCO films with femtosecond laser pulses for structuring thin film solar cells. Applied Physics, 2007; A 89: 161-163.

13. Tan B, Dalili A, Venkatakrishnan K. High repetition rate femtosecond laser nano-machining of thin films. Applied Physics A, 2009; 95: 537-545.

14. Heise G, Englmaier M, Hellwig C, Kuznicki T, Sarrach S, Huber Heinz P. Laser ablation of thin molybdenum films on transparent substrates at low fluences. Applied Physics A: Materials Science \& Processing, 2011; 102(1): 173-178.

15. Volkov AV, Moiseev OYu, Poletayev SD. Precision laser recording on a molybdenum films for diffractive microrelief formation. Computer Optics, 2013; 37(2): 220-225.

16. Poleshchuk AG, Churin EG, Koronkevich VP, Korolkov VP, Kharissov AA, Cherkashin VV, Kiryanov VP, Kiryanov AV, Kokarev SA, Verhoglyad AG. Polar coordinate laser pattern generator for fabrication of diffractive optical elements with arbitrary structure. Applied Optics, 1999; 38(8): 1295-1301.

17. Kazanskiy NL. Research and technological center of diffraction optics. Bulletin of Samara Scientific Center of the Russian Academy of Sciences, 2011; 13(4-1): 54-62. [in Russian]

18. Kazanskiy NL. Research and Education Center of Diffractive Optics. Proceedings of SPIE, 2012; 8410: 84100R, doi: 10.1117/12.923233.

19. Grigoryanc AG, Shiganov IN. Laser welding of metals. Moscow: High school Publisher, 1988. 207 p. [in Russian]

20. Kazanskiy NL, Murzin SP, Tregub VI. Optical system for realization selective laser sublimation of metal alloys components. Computer Optics, 2010; 34(4): 481-486. [in Russian] 
21. Kazanskiy NL, Murzin SP, Osetrov YeL, Tregub VI. Synthesis of nanoporous structures in metallic materials under laser action. Optics and Lasers in Engineering, 2011; 49(11): 1264-1267.

22. Doskolovich LL, Kazanskiy NL, Kharitonov SI, Usplenjev GV. Focusators for laserbranding. Optics and Lasers in Engineering, 1991; 15(5): 311-322. 